\title{
REFLEJO DE LA IDENTIDAD NOBILIARIA EN INDIAS EN LOS PROCESOS DE HIDALGUÍA: EL CASO PERUANO ${ }^{1}$
}

\author{
Jorge PÉREZ LEÓN \\ Universidad de Valladolid
}

Recibido: 19/09/2012

Aceptado: 04/10/2012

RESUMEN: La identidad colectiva de la nobleza española era una realidad compleja que agrupaba diferentes conceptos (nobleza e hidalguía, limpieza de sangre y de oficios). A finales de la Edad Moderna el deseo de demostrar este "buen origen" llevaría a muchos de estos nobles a solicitar pruebas de hidalguía. A partir del estudio de estos documentos nos proponemos en este trabajo reconocer esta mentalidad nobiliaria en la América española, de origen netamente castellana pero dotada de sus propias peculiaridades regionales.

PALABRAS CLAVE: Nobleza, identidad, hidalguía, América española, prueba documental.

ABSTRACT: The collective identity of the Spanish nobility was a complex reality that gathered different concepts (nobility and hidalguía, purity of blood and of mechanical crafts). At the end of the Modern Age the desire to demonstrate this "good ascendancy" led many nobles to request their hidalguía proofs. Taking into consideration the research of these documents, in this study we aim to recognize this noble mentality in the Spanish America from this proofs, that although they have got a purely Castilian origin, they were endowed with its own regional peculiarities.

KEYWORDS: Nobility, identity, hidalguía, Spanish America, documentary evidence.

Tradicionalmente, las investigaciones sobre la mentalidad nobiliaria han partido de la imagen proyectada por este estamento usando para ello desde tratados sobre nobleza ${ }^{2}$, textos teóricos que justificaban la preeminencia social del estamento,

\footnotetext{
${ }^{1}$ Esta investigación se ha realizado con el apoyo de una Beca FPI cofinanciada por la Junta de Castilla y León y el Fondo Social Europeo.

${ }^{2}$ Un buen ejemplo es el estudio de Guillén Berrendero sobre la obra del tratadista Juan Benito Guardiola: GuILlÉN BERRENDERO, J. A. (2007). La idea de nobleza en Castilla durante el reinado de Felipe II. Valladolid: Universidad de Valladolid.
} 
hasta obras literarias y teatrales ${ }^{3}$, fuentes que, a pesar de su gran valor a la hora de analizar la opinión popular, no están libres de estereotipos.

Por el contrario, cuestiones como la percepción que el noble tenía de sí mismo o de su propia calidad han merecido escasa atención. Aún más desconocida resulta la realidad de la identidad nobiliaria en la América española, donde el estudio de la nobleza se ha visto frecuentemente relegada por la perspectiva socioeconómica en clave elitista.

Los procesos de hidalguía, por su carácter de prueba nobiliaria, ofrecen una oportunidad única para estudiar cuáles eran y de qué forma se manifestaban estos signos externos de la nobleza hispana. A finales del Antiguo Régimen la reputación ya no dependía exclusivamente del nacimiento sino que factores como la riqueza y los méritos personales estaban cobrando mayor importancia. Es decir, que la identidad nobiliaria, como realidad mental compleja, se construía a partir de distintos elementos emanados de la estima familiar y personal. Para aproximarnos a esta cuestión hemos partido del análisis de la información (forma de denominarse, ascendencia acreditada, oficios, cargos y honores) reflejada en los poderes notariales, peticiones elevadas a los tribunales o las probanzas e informaciones de filiación contenidas en estos procesos judiciales.

Además, con el fin de analizar las diferencias y semejanzas con la realidad peninsular, hemos consideramos de interés centrar nuestro análisis en los procesos de hidalguía promovidos por indianos en la Real Chancillería de Valladolid, concretamente los de personas naturales o residentes en el Perú ámbito en el que hemos priorizado nuestras investigaciones.

\section{IDENTIFICACIÓN DEL PRETENDIENTE: APELLIDOS Y FILIACIONES}

Aunque la regulación actual en la forma y el orden de los apellidos (paternomaterno) se impuso ya avanzado el siglo XIX ello no significa que el aparente "desorden" de nombres y apellidos predominante hasta entonces careciese de sentido sino que, por el contrario, eran una seña de identidad para la persona que los asumía como propios.

En lo tocante a la utilización y disposición de los apellidos con que aparecen presentados los pretendientes no cabe duda que, lejos de ser una cuestión aleatoria, sigue una serie de pautas que alteran el conocido orden de la doble filiación

\footnotetext{
${ }^{3}$ En la obra de Juan Antonio Maravall encontramos varios ejemplos representativos. MARAVALL, J. A. (1983). La cultura del Barroco: análisis de una estructura histórica. Barcelona: Ariel; (1986). La literatura picaresca desde la historia social (siglos XVI y XVII), Madrid: Taurus.
} 
paterno-materna. Un factor fundamental a considerar es que con los procesos de hidalguía se buscaba acreditar la posesión de la hidalguía de sangre por línea paterna ya que, tal y como señalan Las Siete Partidas ${ }^{4}$, esta se transmitía exclusivamente por varonía ${ }^{5}$, motivo por el cual la inmensa mayoría de los pretendientes aparecerá registrada únicamente con el primer apellido paterno ${ }^{6}$.

De hecho en aquellos casos donde se refieren dos apellidos estos suelen estar asociados a la ascendencia paterna, fruto de la consolidación de un apellido compuesto que identificaba a un determinado grupo familiar. Generalmente, el origen de estas peculiares composiciones se remontaba a muchas generaciones atrás. En la familia del comerciante guipuzcoano Martín Antonio de Aramburu y Echeverría se venían utilizando los dos apellidos paternos desde su quinto abuelo ${ }^{7}$. Curiosamente, cuando años más tarde Martín Antonio postuló para un hábito de la orden de Santiago modificó tal costumbre retomando la bilinealidad paternomaterna, identificándose como Aramburu y Echazarreta, acreditando así la hidalguía y la limpieza por ambas líneas ${ }^{8}$. Por lo tanto, puede observarse como la

${ }^{4}$ En ellas se expone que: “... la mayor parte de la hidalguía ganan los hombres por la honra de los padres, pues cuando la madre sea villana y el padre hijodalgo, hijodalgo es el hijo que de ellos naciere, y por hidalgo se puede contar, mas no por noble, mas si naciere de hijadalgo y de villano, no tuvieron por derecho que fuese contado por hijodalgo". Libro de las Siete Partidas, P. II, Tít. XXI, 1. III.

${ }^{5}$ Esta concepción patrilineal que priorizaba la línea agnada sobre la cognada parte de la idea de que el varón era parte activa determinante del nuevo ser mientras que la mujer era mero receptor pasivo. MEnÉndez PidAl de NAVAscués, F. (2008). La nobleza en España: ideas, estructuras, historia. Madrid: Fundación Cultural de La Nobleza Española, p. 58.

${ }^{6}$ No obstante, también encontramos casos en los que se presentan con ambos apellidos de forma simultánea (paterno-materno), especialmente cuando se pretendía acreditar la hidalguía por ambas líneas. Es el caso de los hermanos Loredo y Suazo, naturales de Santurce y residentes en Perú y Cádiz, hijos de Antonio de Loredo y María Ángela de Suazo. Real provisión de vizcaínía de Mariano, Juan Matías y José Valentín de Loredo y Zuazo, sus hijos, representados por $\mathrm{M}^{\mathrm{a}}$ Ángela de Suazo, como tutora y curadora de sus hijos (1776). Archivo de la Real Chancillería de Valladolid [en adelante ARChV], Registro-Vizcainías, C. 9-45.

${ }^{7}$ Martín Antonio, natural de Zumárraga, era hijo de hijo de Francisco de Aramburu Echeverría y de Lorenza de Echazarreta; nieto paterno de Francisco Aramburu y Echeverría y de Francisca de Zaldúa; bisnieto paterno de Domingo de Aramburu y Echeverría y de Anastasia de Alzola; tercer nieto de Sebastián de Aramburu y de María Pérez de Orá; cuarto nieto de Bernardo de Aramburu Echeverría y de Magdalena de Cortaverría; y quinto nieto de Domingo de Aramburu y de María Pérez de Oyanguren. Expediente provisional de hidalguía de Martín Antonio de Aramburu y Echeverría, natural de Zumárraga y vecino y del comercio de Lima (1806). ARChV, Sala Hijosdalgo-pleitos, C. 1030-16.

${ }^{8}$ En la genealogía expuesta junto a la cédula de merced de hábito el pretendiente aparece como "don Martín de Aramburu y Echevarrieta (sic)", fruto sin duda de la confusión entre el segundo apellido paterno (Echevarría o Echeverría) y el primer apellido materno (Echevarrieta según esta 
composición de apellidos, lejos de dejarse al azar, era una respuesta a intereses y necesidades concretas. Estos apellidos compuestos, aunque característicos en aquellas familias que poseían algún vínculo o mayorazgo que imponía la perpetuación de los apellidos ${ }^{9}$, también era frecuente en familias de menor lustre, como la del riojano Domingo Mauricio de Besoitagoena y Berrobeitia, hijo de un carpintero $^{10}$.

En el caso de los apellidos vascongados conviene recordar su origen toponímico, pues designan a un mismo tiempo una localidad y la casa solar asociada a ella, entroncando de este modo al pretendiente con dichos solares de nobleza. Así, por ejemplo, el citado Aramburu Echeverría decía descender por sus apellidos de las casas de Aramburu-Echeverría, Orá y Alzola, ubicadas en la villa de Zumárraga; de la de Zaldúa y Guridi en Legázpia; de la de Santa Cruz en Oñate; de la de Lasa en Astigarreta; de la de Garín en Beasaín; de la de Maíz en Ataun; de la de Echazarreta y Aranzadi en Ezquioga ${ }^{11}$.

Los apellidos también tuvieron una notable importancia en la concreción de una identidad nobiliaria más o menos fantasiosa, alimentando toda clase de mitos y leyendas que respaldasen la buena reputación de un apellido. Las deposiciones de testigos, reflejo de la opinión popular, arrojan datos interesantes en este sentido ya que, ocasionalmente, ponen en evidencia la importancia del apellido como forjador y transmisor de la idea de linaje en la conciencia colectiva. En el proceso del montañés Juan de la Roza, contador de las minas de Huancavelica, uno de los

genealogía, Echazarreta según el proceso de hidalguía). Expediente para la concesión del título de caballero de Santiago (1830). Archivo Histórico Nacional [en adelante AHN], Órdenes, Santiago, exp. 8875 .

${ }^{9}$ Es el caso de Alonso Carrió y Lavandera, gijonés avecindado en Lima. El mayorazgo de los Carrió Lavandera se hallaba instituido en la villa de Gijón y constaba de "ciertas tierras y montes situadas en el pueblo de Jove y otras partes y en una casa principal y otra más que están en la villa de Gijón, agregando a dicho mayorazgo una de las varas de regidor perpetuo de dicha villa y el patronato del curato de San Juan de Veriña...” Testamento de Alonso Carrió y Lavandera. Lima, 17 de octubre de 1767. Archivo General de la Nación del Perú [en adelante AGN], Colección Moreyra, D1. 16-443, ff. $2 \mathrm{v}-3 \mathrm{r}$.

10 Declaración de Francisco Olabe Larrinaga, vecino de Bérriz (1802). Real Provisión de vizcainía de Domingo Mauricio de Besoitagoena y Berrobeitia, residente en la ciudad de Camaná y natural de la villa de Lumbreras de Cameros (1802). ARChV, Registro-Vizcainías, C. 4-39.

${ }^{11}$ Declaraciones de los testigos interrogados en Zumárraga (1805). ARChV, Sala Hijosdalgopleitos, C. 1030-16. 
testigos llega a aseverar que el apellido Alonso (cuarto apellido del pretendiente) era "tan distinguido que por notorio se dice desciende de los godos"12.

Frente a la diversidad en el uso y disposición de los apellido apreciada entre los pretendientes peninsulares, los americanos mantienen un criterio más unitario, expresando la bilinealidad, ya que sus apellidos maternos evocaban cierto prestigio en Indias. Es el caso del limeño Pablo Páez de Jaramillo y Céspedes que descendía por línea materna de José de Céspedes, uno de los conquistadores del Perú ${ }^{13}$; o de Juan Manuel de Sarriá Cárdenas Segura y Rojas que afirmaba que su quinto abuelo materno era Diego de Rojas, "uno de los más ilustres conquistadores de los reinos de Chile y Perú" ". Por su parte, los hermanos Gallo Díaz Calvo, hijos de Manuel Gallo Díaz de Tudanca y de $\mathrm{M}^{\mathrm{a}}$ Francisca García Calvo, agregaron a los dos apellidos paternos (prescindiendo del "de Tudanca") el segundo apellido de la madre, perteneciente a su vez al abuelo materno, secretario y alguacil mayor del Santo Oficio de Lima lo que remarcaba su limpieza de sangre ${ }^{15}$. En este sentido una notable excepción es el caso de la guayaquileña Francisca Lecuona y Alberro, una de las pocas mujeres que acudieron a la Real Chancillería a acreditar su hidalguía, que figura con los dos apellidos de su padre, el guipuzcoano José Antonio Lecuona y Alberro, omitiendo el apellido de la madre, hija nada menos que del regidor perpetuo de Guayaquil Francisco de Ilumbe ${ }^{16}$. Se trata nuevamente de una adaptación de los apellidos ya que la interesada solo pretendía dar testimonio de su entronque con la nobleza guipuzcoana.

Obviamente, estas enrevesadas y elaboradas composiciones de apellidos, muchas de ellas confeccionadas expresamente para los procesos de hidalguía, no se

12 Declaración de Francisco de San Juan, vecino de Ajo (1787). ARChV, Sala Hijosdalgo-pleitos, C. $1175-25$.

13 Según figura en la filiación expuesta en su petición inicial ante la Sala de Hijosdalgo. Expediente provisional de hidalguía de Pablo Páez de Jaramillo y Céspedes (1789). ARChV, Sala Hijosdalgo-pleitos, C. 996-3.

${ }^{14}$ Testimonio de los documentos de nobleza, empleos honoríficos, méritos y servicios de algunos individuos de la ascendencia de la línea de María Cayetana de Rojas, abuela materna de Juan Manuel de Sarriá. Cádiz, 24 de marzo de 1791. Se incluye además un traslado del párrafo de los Comentarios de los Incas (sic) del Inca Garcilaso de la Vega en el que se cita a Diego de Rojas ( $5^{\circ}$ abuelo maternomaterno). Documentos presentados como prueba en el Expediente provisional de hidalguía de Juan Manuel Sarriá y Cárdenas, conde de Casa Sarriá (1793). ARChV, Sala Hijosdalgo-pleitos, C. 119147.

15 Expediente provisional de hidalguía de Gabriel, Manuel y Andrés Gallo Díaz Calvo (1790). ARChV, Sala Hijosdalgo-pleitos, C. 996-5.

${ }^{16}$ Información ad perpetum rei memoriam de Francisca Lecuona y Alberro (1778). ARChV, Sala Hijosdalgo-pleitos, C. 1047-28. 
correspondían con los que los interesados utilizaban en su vida cotidiana. Por ejemplo, Francisco Julián Ochoa de Berrio y Gasteas se identificaría pocos años después en su propio testamento como Francisco Julián de Berrio ${ }^{17}$; el montañés Domingo de la Guerra Sánchez de Cosío, hijo de Pedro de la Guerra Sánchez de Cosío y de Dominga González del Alcalde, firmaría en su poder para testar como Domingo Sánchez de Cosío ${ }^{18}$.

Para obtener el ansiado despacho de hidalguía tan importante como los apellidos era preciso proponer una correcta relación de su ascendencia. Desarrollada por los procuradores en las peticiones -ayudados de la información suministrada en los poderes o por los propios apoderados- orientaba a los jueces sobre la filiación que la parte interesada pretendía acreditar: "hijo de", "nieto de", etc. Aunque la gran mayoría de los pretendientes estudiados -procedentes de familias de escaso abolengo- se limitaba a probar su hidalguía de sangre hasta los abuelos o bisabuelos paternos, aquellos que tenían una ascendencia más lustrosa y esclarecida gustaban de relatar largas genealogías sembradas de personajes y cargos de renombre. José Martín de Bustamante y Quevedo, junto a su hermano Alejandro, remontaron su genealogía hasta su cuarto abuelo paterno-paterno, Martín de Bustamante y la Vega, maestre de campo de los Reyes Católicos ${ }^{19}$.

Para justificar estas largas genealogías se exhibían toda clase de pruebas, generalmente antiguas ejecutorias despachadas a favor de familiares tiempo atrás ${ }^{20}$,

${ }^{17}$ Real Provisión de vizcainía de Francisco Julián Ochoa de Berrio y Gasteas, natural de la villa de Elorrio, capitán de milicias de caballería de la ciudad de Camaná en Perú (1797). ARChV, Registro-Vizcainías, C. 12-19. Testamento de Francisco Julián de Berrio. Cádiz, 22 de agosto de 1800. Archivo Histórico Provincial de Cádiz [en adelante AHPC], Protocolos Notariales Cádiz, Manuel Sáenz, prot. 412, ff. 560r-564v.

18 Expediente provisional de hidalguía de Domingo de la Guerra Sánchez de Cosío (1722). ARChV, Sala Hijosdalgo-pleitos, C. 926-78. Poder para testar otorgado por Domingo Sánchez de Cosío. Lima, 18 de enero de 1744. AGN, Notarial, Francisco Estacio Meléndez, prot. 368, ff. 53v$55 \mathrm{r}$.

19 Expediente provisional de hidalguía de Alejandro y José Martín Bustamante y Quevedo, naturales de Cartes y residentes en Jaén y Lima respectivamente (1765). ARChV, Sala Hijosdalgopleitos, C. 1131-3.

${ }^{20}$ El conde de Vallehermoso acudiría en 1753 a la Sala de Hijosdalgo reclamando su entronque con la ejecutoria de hidalguía despachada en favor de su tío Francisco Ortiz de Foronda en su litigio con el concejo alavés de Foronda en el año de 1682. Poder notarial otorgado por Pedro Ortiz de Foronda, conde de Vallehermoso. Madrid, 22 de octubre de 1753. ARChV, Sala Hijosdalgo-pleitos, C. 1812-4. 
pero también otras menos comunes como privilegios de hidalguía ${ }^{21}$ e incluso correspondencia privada ${ }^{22}$. Las alusiones a servicios prestados a la Corona por parte de los antepasados deben entenderse como una reivindicación de los méritos acumulados por la familia a lo largo de sucesivas generaciones. No se entendían únicamente como actos positivos de hidalguía al uso sino también como pruebas de su tradicional fidelidad y predisposición al real servicio, vinculando así nobleza de linaje y de servicio ${ }^{23}$.

Haciendo gala de sus peculiaridades frente a la hidalguía castellana era habitual que los vizcaínos expusiesen ante la Sala de Vizcaya una filiación que, como mínimo, llegase hasta los cuatro abuelos, dando la misma entidad a ambas líneas. Esto ponía de manifiesto su procedencia de Vizcaya por los cuatro costados y, por ende, su calidad como "nobles hijosdalgo vizcaínos originarios". En la Sala de Hijosdalgo solamente los alaveses originarios de la Tierra de Ayala tenían la costumbre de probar su hidalguía por ambas líneas ya que en esta comarca, al igual que en Vizcaya, solo podía avecindarse gente noble. De modo estos ayaleses no solo exponían filiaciones por ambas líneas (generalmente hasta los cuatro abuelos) sino que remontaban sus probanzas hasta los bisabuelos paternos y maternos ${ }^{24}$.

${ }^{21}$ Privilegio de hidalguía concedido por los Reyes Católicos a Hernán Pérez Coronel y a sus hijos y descendientes, vecino y regidor de la ciudad de Segovia. Peñafiel, 25 de julio de 1492. Presentado como prueba en el expediente provisional de hidalguía de Juan Manuel Sarriá y Cárdenas (1793). ARChV, Sala Hijosdalgo-pleitos, C. 1191-47.

${ }^{22}$ Cartas misivas fechadas en 1429 y 1445 de Juan II dirigidas al capitán don Pedro (noveno abuelo del pretendiente); Carta de Luis de Requesens (Leyden, 1574) y otra de Juan de Austria (Namur, 1578), ambas dirigidas al maestre de campo Francisco Menéndez (hermano del quinto abuelo del pretendiente). Se presenta como prueba una carta misiva del Duque de Medina Sidonia (Lisboa, 1588), al mando de la Armada, dirigida al Almirante Antonio Menéndez de Valdés (hijo de quinto abuelo). Presentadas como pruebas en el Expediente provisional de hidalguía de Toribio Menéndez Valdés y Cornellana, natural de Gijón y residente en Lima (1772). ARChV, Sala Hijosdalgo-pleitos, C. 973-32.

23 Montojo Montojo, V. Hernández Franco, J. (2001). «Patronazgo real y familias urbanas: comportamientos de poder (Cartagena, siglos XVII-XVIII)». En Chacón Jiménez, F. y Hernández Franco, J. (eds.). Familia, poderosos y oligarquías [Seminario Familia y élite de poder en el Reino de Murcia, siglos XV-XIX]. Murcia: Universidad de Murcia, pp. 83-85.

${ }^{24}$ Vid. peticiones iniciales de los expedientes de hidalguía de Antonio Juan y Antonio Miguel de Arriaga y Gurvista, naturales de Lezama y vecinos de Buenos Aires y Lima respectivamente (1774). ARChV, Sala Hijosdalgo-pleitos, C. 905-19; Felipe Santiago, Tomás Domingo y Domingo Millán de Acha y Urruchi, naturales de Menoyo y vecinos de Salmantón, México y Lima respectivamente (1785). ARChV, Sala Hijosdalgo-pleitos, C. 993-2; Matías Antonio y Juan José de Arechavala y Leal de Ibarra, naturales de Retes de Llanteno y residente el segundo en Arequipa (1788). ARChV, Sala Hijosdalgo-pleitos, C. 1189-45. 
A pesar de la importancia que tenía exponer correctamente la filiación lo cierto es que en algunos casos se aprecian sorprendentes contradicciones. Al incoar pleito de hidalguía los hermanos Juan Antonio y Pedro Moreno -este último ausente en Lima-sostenían que sus terceros abuelos eran Juan Moreno y Marina Gil ${ }^{25}$. Sin embargo, una vez iniciadas las diligencias, Juan Antonio emitiría un segundo poder corrigiendo su ascendencia y afirmando que aquellos no eran los terceros abuelos sino los cuartos ${ }^{26}$. Este no era un error insignificante ya que Juan Moreno era una pieza fundamental para justificar su hidalguía al ser el primer antepasado asentado como caballero divisero en el solar de Tejada. A pesar de lo sospechosa que resulta esta apresurada recomposición del árbol genealógico los alcaldes de Hijosdalgo no pusieron impedimento alguno, fallando en favor de los pretendientes. Este caso da cierta idea no solo de la falta de rigor de algunas informaciones presentadas en el tribunal sino también de la facilidad con que podrían construirse filiaciones a la medida de los solicitantes.

Un último aspecto a considerar en la presentación de los pretendientes es el uso del "don" como tratamiento, que había ido perdiendo su valor como indicio de distinción a lo largo de la Edad Moderna, especialmente en los núcleos urbanos ${ }^{27}$. No obstante, durante el siglo XVIII todavía podemos encontrar espacios donde mantenía su antiguo significado, principalmente en lugares refractarios a los cambios como eran los núcleos rurales, tanto aquellos con división de estados ${ }^{28}$

${ }^{25}$ Poder notarial otorgado por Juan Antonio Moreno, por sí y en nombre de su hermano Pedro. Villoslada de Cameros, 7 de octubre de 1793. ARChV, Sala Hijosdalgo-pleitos, C. 279-11.

${ }^{26}$ Poder notarial otorgado por Juan Antonio Moreno, por sí y en representación de su hermano Pedro Moreno, vecino de Lima. Arroyo del Puerco, 14 de enero de 1794. Ibídem.

${ }^{27}$ En sus Cartas Marruecas José Cadalso realiza una ácida crítica sobre la generalización del don y la pérdida de significado de los tratamientos: "Mas es, que la multiplicidad del don lo ha hecho despreciable entre la gente de primorosa educación. Llamarle a uno don Juan, don Pedro o don Diego, a secas, es tratarle de criado; es preciso llamarle señor don, que quiere decir dos veces don..." CAdalso, J. (edición, prólogo y notas de Juan Tamayo y Rubio) (1935). Cartas Marruecas. Madrid: Espasa-Calpe, Carta XII, p. 268. Según Jaime de Salazar y Acha "en el siglo XVIII la inmensa mayoría de los hidalgos, salvo en el norte de España donde eran muy numerosos y pobres, recibía el citado tratamiento. Igualmente todos los clérigos, los funcionarios reales de cierto rango, los abogados, los oficiales del ejército $\mathrm{y}$, en general, toda persona que gozara de un nivel económico y social de cierto relieve, perteneciera o no a la nobleza". Coincidimos parcialmente en su opinión aunque discrepamos en su afirmación referente a su uso entre los hidalgos del norte de España. SAlAZAR y ACHA, J. (2006). Manual de genealogía española. Madrid: Ediciones Hidalguía, p. 303.

${ }^{28}$ En el pleito de hidalguía de Gabriel Velasco y Quijano, natural de Buenavista y vecino de Lima, encontramos los siguientes deponentes de su parte en el año de 1773: Domingo Martín, de oficio labrador y del estado general; Alonso Ayuela, pastor de ganado lanar y con su hacienda y es del estado general; Mateo Gutiérrez, se mantiene de sus bienes y hacienda y es del estado general; Juan de Treceños, se mantiene de sus bienes y hacienda y es del estado general; Juan Martín, labrador que 
como en los que solo existía estado noble ${ }^{29}$. Pero lo cierto es que el uso generalizado del tratamiento terminó por trasladarse a ámbitos más formales como los tribunales. Aunque las primeras apariciones de esta partícula como mera fórmula de cortesía en los procesos de hidalguía se remontan a mediados del siglo XVII no sería hasta la siguiente centuria cuando se extendió de manera uniforme antecediendo al nombre del pretendiente. Poderes notariales y peticiones nos permiten comprobar que la inmensa mayoría de los otorgantes y pretendientes aparecen precedidos por la partícula "don" si bien durante el primer tercio de siglo XVIII todavía encontramos excepciones, prueba de que dicha práctica todavía no se hallaba firmemente consensuada ${ }^{30}$. Poco a poco terminó cristalizando su uso como fórmula de cortesía en los encabezamientos de las peticiones, desprovisto de todo valor como indicio de distinción social. Prueba de ello es que personas con un estatus social elevado, como es el caso de nobles titulados, recibían también el tratamiento de "don" y no el de "Señor don" que se confería en la época a personas de su posición, "homogeneizando" el tratamiento dado a todos los pretendientes ${ }^{31}$.

vive de sus bienes y hacienda y del estado general, todos vecinos de Buenavista. De la vecina villa de Cervera de Pisuerga se presentaron: José Montero, vive y mantiene de sus bienes y hacienda y del estado general; Lucas Cardaño, maestro herrador, albéitar y mesonero y del estado general; don Manuel Antonio Gil, presbítero y capellán en la villa de Cervera; Fray Francisco José Antonio Cosío Vozmediano, caballero del hábito de San Juan [de Jerusalén], prior de Arbejal y vicario general por su sagrada religión en el bailiaje de Nueve Villas -hoy Población de Campos; don Juan Gómez Dosal, vive y se sustenta de sus bienes y hacienda, su oficio de labrador que es del estado noble. Entre los testigos presentados a petición del fiscal de la Real Chancillería en las diligencias de cotejo tenemos a Damián de Cenera (o Cervera), labrador y mercader, estado de pecheros; don Isidoro Morante, labrador e hijodalgo; don Francisco Rodríguez de las Conchas, cerero que se mantiene con su tienda abierta, familiar del Santo Oficio de Valladolid y del estado de caballeros hijosdalgo, todos vecinos de Cervera de Pisuerga. ARChV, Sala Hijosdalgo-pleitos, C. 1254-14.

${ }^{29}$ En el expediente provisional de hidalguía de José de Santiuste (1769) testifican los siguientes vecinos de la villa de Argoños (Trasmiera) donde todos los vecinos eran hidalgos: don Bernardino del Solar; don Agustín del Valle; don Gregorio del Solar, procurador general de Argoños; don José de la Vega. ARChV, Sala Hijosdalgo-pleitos, C. 1139-48.

${ }^{30}$ Es el caso de los asturianos Juan y Alonso García de la Puente, naturales de Corias y residentes en Lima, presentados únicamente como capitanes (1709). ARChV, Sala Hijosdalgo-pleitos, C. 105622; o de Domingo Antonio de Sama, natural de Piedra y residente también en Lima (1719). ARChV, Sala Hijosdalgo-pleitos, C. 913-6; o del criollo Pedro José Ibáñez de García, que enunciado como "don" en el poder otorgado, aparece sin dicho tratamiento en la petición realizada ante los alcaldes de Hijosdalgo probablemente porque el procurador no lo estimó conveniente (1722). ARChV, Sala Hijosdalgo-pleitos, C. 1075-73.

${ }^{31}$ Un ejemplo es el de Juan Manuel Sarriá y Cárdenas, conde de Casa Sarriá, quién en el poder notarial otorgado para obtener el despacho de una real carta ejecutoria en la Sala de Hijosdalgo es identificado como "Señor don Juan Manuel de Sarriá y Cárdenas, conde de Casa Sarriá". Cádiz, 16 de septiembre de 1793. Sin embargo, en las peticiones y autos de dicho tribunal figura únicamente como "don Juan Manuel de Sarriá y Cárdenas, conde de Casa Sarriá". ARChV, Sala Hijosdalgo-pleitos, C. 
Jorge Pérez Léon

\section{SIGNIFICADO DE LAS OCUPACIONES, CARGOS Y DISTINCIONES DE NOBLEZA}

En la sociedad del Antiguo Régimen la ocupación o cargo desempeñado por un individuo era también un signo de estatus ya que la reputación personal quedaba indisolublemente unida a la buena opinión del oficio ejercido. Esto queda reflejado en los procesos de hidalguía, donde se busca reforzar, al menos moralmente, las pretensiones de nobleza de los pretendientes destacando los méritos personales contraídos mediante ocupaciones, cargos o títulos honoríficos. Por el contrario, también se detectan silencios acerca de su propia dedicación por lo que debemos considerar que esta información, adicional y voluntaria, tenía fines puramente promocionales $^{32}$.

Tabla 1. Provistos en Indias en los procesos de hidalguía

\begin{tabular}{|c|c|c|}
\hline Pretendientes (Origen) & $\begin{array}{c}\text { Inicio } \\
\text { proceso }\end{array}$ & Presentado como \\
\hline Benavente y Ugarte, Gregorio (P) & 1723 & $\begin{array}{l}\text { Gobernador y Capitán General de la provincia de Canas y } \\
\text { Canches }\end{array}$ \\
\hline Frade y Sierra, Juan Agustín (P) & 1752 & $\begin{array}{l}\text { Caballerizo de campo; Oficial Real de las Reales Cajas de } \\
\text { Lima }\end{array}$ \\
\hline Arriaga Gurvista, Antonio Miguel (P) & 1774 & $\begin{array}{l}\text { Administrador general de las alcabalas y almojarifazgo de } \\
\text { Lima }\end{array}$ \\
\hline Ortiz de Rozas, Domingo Manuel (P) & 1779 & Corregidor y Justicia Mayor de la prov. de Cotabambas \\
\hline Rosa (o Roza), Juan de la (P) & 1787 & Contador General de Azogues de la villa de Huancavelica \\
\hline Arechavala, Juan José de (P) & 1788 & Administrador de la renta de Correos \\
\hline Gorbea y Vadillo, José Lucas (P) & 1790 & Fiscal de lo civil de la Real Audiencia de Lima \\
\hline Portura y Landázuri, Pablo de (P) & 1796 & Visitador de las Cajas Reales de Arequipa \\
\hline
\end{tabular}

FuENTE: ARChV, Sala Hijosdalgo-pleitos, C. 259-7, 905-19, 1105-2, 1161-51, 1175-25, 1182-23, 1189-45 y 1286-14; Registro-Vizcainías, C. 14-15. P.: Peninsular; Cr: Criollo

Para entender el porqué de su selectiva mención u omisión debemos buscar qué trascendencia tenían tales oficios, empleos y honores en la mentalidad nobiliaria. De un total de 98 pretendientes estudiados apenas 20 de ellos indican las ocupaciones o cargos que desempeñaban en el momento de iniciar el proceso en la Real Chancillería. Encontramos, por orden de importancia, cargos en la administración colonial (8), comerciantes (5), gentes de letras (5) y, por último, clérigos (2). Dada la estimación social de la mayoría de estas ocupaciones resulta

1191.47. O el de Juan Esteban de la Puente y Castro, marqués de la Puente y Sotomayor, tratado como "Señor don" en el poder otorgado a favor de sus tías, vecinas de Trucíos. Madrid, 27 de abril de 1782. ARChV, Registro-Vizcainías, C. 14-18.

32 Este comportamiento se aprecia igualmente en los despachos de títulos nobiliarios. Vid. Felices DE LA FueNTE, $M^{\mathrm{a}}$ del M. (2010). «Silencio y ocultaciones en los despachos de los títulos nobiliarios». Chronica Nova, 36, pp. 229-252. 
evidente que estas referencias explícitas se presentan como argumentos en favor del solicitante, proporcionándonos datos fundamentales sobre su estatus.

La presencia de cargos en la administración indiana (TABLA 1), especialmente corregidores y agentes de la Real Hacienda (oficiales de las Cajas Reales y de sus diferentes ramos) no es casual ya que pone de relieve, ante un tribunal regio, una obligación de la nobleza: el servicio al monarca ${ }^{33}$.

Un segundo grupo, seis individuos, está formado por aquellos presentados como comerciantes en las peticiones elevadas ante los tribunales, generalmente identificados como "vecinos y del comercio" de determinada ciudad.

Tabla 2. Comerciantes en los procesos de hidalguía

\begin{tabular}{lcl}
\hline \multicolumn{1}{c}{ Pretendientes (Origen) } & Inicio & \multicolumn{1}{c}{ Presentado como } \\
\hline Bustamante Quijano, Juan Antonio (P) & 1758 & "Capitán del Batallón y comercio de Lima" \\
Uría, Antonio de (P) & 1791 & "Vecino y comerciante de la ciudad de Lima" \\
Aramburu y Echeverría, Martín de (P) & 1806 & "Vecino y del comercio de Lima" \\
Arróspide, Juan Bautista (P) & 1806 & "Vecino y del comercio de Arequipa" \\
Sanz de Santo Domingo, Lorenzo (P) & 1817 & "Vecino y del comercio de Lima" \\
\hline
\end{tabular}

FuENTE: ARChV, Sala Hijosdalgo-pleitos, C. 956-29, 1030-16 y 1233-21; Registro-Vizcainías, C. 32, 7-69 y 18-17. P.: Peninsular; Cr: Criollo.

A pesar de que el número de comerciantes que aparecen reflejados en los procesos es importante en relación con el número total de ocupaciones referidas en los mismos resulta insignificante si atendemos al número total de pretendientes que realmente ejercía como tal y que no hace mención de ello, síntoma de una masiva e intencionada omisión de esta ocupación. En algunos casos las probanzas aportan indicios en este sentido. Uno de los testigos presentado de parte de Domingo Mauricio de Besoitagoena y Berrobeitia informaba que "anduvo en la escuela de leer y escribir hasta que, instruido, pasó del comercio de la villa de Zafra y desde esta pasó a su residencia a la ciudad de Camaná" ${ }^{34}$; en el caso del alavés Domingo Millán de Acha y Urruchi, de quien se afirma que "se mantuvo por diferentes años en compañía de dicho su tío don Domingo Antonio en la de Sevilla y luego se dedicó al empleo de carrerista para Indias en que al presente se ejercita

33 DíAz DE LA GuARDia y LóPEZ, L. (2003). «El deber de fidelidad al rey como justificación de hidalguía en la nobleza en España e Indias». Anuario Mexicano de la Historia del Derecho, 15, p. 156.

${ }^{34}$ Declaración de Matías Martínez Heredia, regidor vecino de la villa de Lumbreras y capitular (1802). ARChV, Registro-Vizcainías, C. 4-39. 
manteniéndose por ahora en la dicha ciudad de Lima"35. Considerando que la presencia de comerciantes entre los pretendientes a la hidalguía se constata desde principios de la centuria tampoco resulta una cuestión menor el hecho de que la mayor parte de las referencias explícitas hacia este grupo se concentren a finales del siglo XVIII y principios del XIX. Ello indicaría que la aceptación del comercio como actividad honrosa y compatible con la nobleza fue muy tardía ${ }^{36}$.

Aunque, por lo general, eran los propios pretendientes quienes no declaraban su condición de comerciantes encontramos otros casos en los que la responsabilidad de tales omisiones correspondía al procurador. No debemos olvidar que estos letrados, como representantes de los interesados ante los tribunales, eran los responsables de reflejar unos datos $\mathrm{u}$ otros en las peticiones elevadas a los tribunales. Así, Pedro Moreno Benito, que aparece como "del comercio al por mayor de Lima" en su propio poder notarial, constaría en la demanda únicamente como natural de Vinuesa y vecino de $\mathrm{Lima}^{37}$; al igual que Domingo Millán de Acha y Urruchi quien, a pesar de otorgar poder notarial como "residente en ella [Lima] y de su comercio" ${ }^{138}$, aparecería identificado simplemente como "residente en Lima". Habida cuenta que los procuradores trasladaban al pie de la letra a las peticiones la información de interés de los poderes no cabe duda que se trataban de omisiones premeditadas al considerar que la actividad era poco apropiada para asuntos de esta naturaleza.

En cierto modo, los procesos también reflejan el ascenso social de algunos comerciantes exitosos. Juan Manuel de Sarriá Cárdenas, un rico comerciante

${ }^{35}$ Pregunta número ocho del interrogatorio a los testigos del Expediente provisional de hidalguía de los hermanos Acha y Urruchi (1785). ARChV, Sala Hijosdalgo-pleitos, C. 993-2.

${ }^{36} \mathrm{Al}$ igual que sucedió con el rechazo social hacia los oficios mecánicos tras la Real Cédula de 1783. Guillamón Álvarez, J. (1981). Honor y honra en la España del siglo XVIII. Madrid: Universidad Complutense de Madrid, pp. 129-142.

${ }^{37}$ En su poder notarial figura como "don Pedro Moreno, del comercio al por mayor de Lima". Poder notarial otorgado por Pedro Moreno. Lima, 31 de mayo de 1790. ARChV, Sala Hijosdalgopleitos, C. 279-11. Encontramos casos semejantes en otros territorios americanos. Así, por ejemplo, en el Expediente provisional de hidalguía de los hermanos Gabriel y Damián Gutiérrez de Terán (1782), ambos pretendientes otorgan poder notarial conjunto como "vecinos, mercaderes y almaceneros en esta capital, naturales del valle Polaciones, Montañas de Santander, Diócesis de Palencia”, mientras que en las peticiones del procurador ante los alcaldes de Hijosdalgo figuran como "vecinos de la ciudad de México y naturales y originarios del valle Polaciones, Montañas de Santander, Diócesis de Palencia". ARChV, Sala Hijosdalgo-pleitos, C. 1160-1.

38 Poder notarial otorgado por Domingo Millán de Acha y Urruchi. Lima, 26 mayo 1786. ARChV, Sala Hijosdalgo-pleitos, C. 993-2. 
limeño asentado y matriculado en el consulado gaditano ${ }^{39}$, había comprado su título nobiliario de conde de Casa Sarriá apenas un año antes de acudir a la Real Chancillería. En Lima encontramos al poderoso naviero y comerciante montañés Isidro Abarca Gutiérrez. En el momento de acudir a la Real Chancillería junto a su hermano Joaquín acababa de obtener el hábito de la orden de Santiago ${ }^{40}$ y poco tiempo después contraería matrimonio con la condesa de San Isidro.

Tabla 3. Gente de letras en los procesos de hidalguía

\begin{tabular}{|c|c|c|}
\hline Pretendientes (Origen) & $\begin{array}{c}\text { Inicio } \\
\text { proceso }\end{array}$ & Presentado como \\
\hline $\begin{array}{lrr}\text { Castañeda } & \text { y } & \text { Armendáriz, } \\
\text { Sebastián de }(\mathrm{Cr}) & \end{array}$ & 1715 & Colegial del Colegio de San Martín de Lima \\
\hline $\begin{array}{l}\text { Inguanzo y } \quad \text { Córdoba, José } \\
\text { Casimiro }(\mathrm{Cr})\end{array}$ & 1723 & $\begin{array}{l}\text { Abogado de la Real Audiencia de Lima y examinador sinodal } \\
\text { del obispado de la ciudad de Trujillo }\end{array}$ \\
\hline $\begin{array}{l}\text { Icaza y Caparroso, José Gabriel de } \\
\text { (Cr) }\end{array}$ & 1782 & Abogado de las Reales Audiencias de Santa Fe y Quito \\
\hline $\begin{array}{l}\text { Valdés y Vela-Patiño, Juan } \\
\text { Jerónimo (Cr) }\end{array}$ & 1791 & $\begin{array}{l}\text { Abogado de la Real Audiencia de Lima y cura vicario de la } \\
\text { Doctrina de Tapo }\end{array}$ \\
\hline Fuente, Manuel Antonio de la $(\mathrm{P})$ & 1794 & $\begin{array}{l}\text { Colegial del Real Seminario conciliar de San Carlos en } \\
\text { Trujillo }\end{array}$ \\
\hline
\end{tabular}

FUENTE: ARChV, Sala Hijosdalgo-pleitos, C. 925-24, 1006-47, 1071-24 y 1191-30; RegistroVizcainías, C. 8-40. P.: Peninsular; Cr: Criollo.

Queremos detenernos finalmente en aquellos casos en los que se especifica la condición de abogado (3) o de colegial (2) de los pretendientes, todos ellos -a excepción de Manuel Antonio de la Fuente- de origen criollo. Esto contrasta con la inclinación de los pretendientes peninsulares hacia el comercio o la administración. Brading sostiene que el seguimiento de esas carreras profesionales debe interpretarse lisa y llanamente como un mecanismo de consolidación del estatus de los hijos $^{41}$. La admisión en instituciones como colegios mayores o seminarios

${ }^{39}$ Ruiz Rivera, J. B. (1988). El consulado de Cádiz. Matrícula de comerciantes (1730-1823). Cádiz: Diputación Provincial de Cádiz, p. 204.

40 En la petición inicial del expediente provisional de hidalguía figuran como "don Isidro de Abarca, caballero del Orden de Santiago, y don Joaquín de Abarca, su hermano, residentes en la ciudad de Lima en el vuestro reino del Perú" (1776). ARChV, Sala Hijosdalgo-pleitos, C. 977-23.

${ }^{41}$ Brading, D. A. (1975). Mineros y comerciantes en el México borbónico, (1763-1810). México: Fondo de Cultura Económica, p. 404. Entre los pretendientes hallamos varios ejemplos de letrados cuyos progenitores eran comerciantes. Es el caso de Gabriel Gallo Díaz Calvo, natural de Lima e hijo del comerciante burgalés Manuel Gallo Díaz de Tudanca; o del también limeño Juan Jerónimo Valdés y Vela-Patiño, hijo del asturiano Juan Antonio Valdés López Sierra. 
reales era socialmente reconocida como un indicio de nobleza, especialmente en América donde no existían actos de distinción al uso de la Península ${ }^{42}$. No obstante, y siguiendo la opinión de Fayard, también hemos de considerar que la condición principal para ingresar en un colegio mayor era la limpieza de sangre, no la nobleza ${ }^{43}$. Es más, en origen, los colegios mayores recogían en sus estatutos fundacionales la expresa prohibición de admitir a jóvenes hidalgos ${ }^{44}$ si bien esta disposición fue sistemáticamente incumplida y acabaron siendo copados por miembros de la nobleza. Más razonable desde el punto de vista jurídico-nobiliario resulta la mención de la abogacía como carrera honorable ya que todo aquel que pretendiese tomar asiento en los estrados de las audiencias a título de noble debía acreditar dicha condición ${ }^{45}$.

En resumen, todo parece indicar que la ocupación era un dato circunstancial del que los interesados prescindían siempre y cuando no sirviese para respaldar sus pretensiones nobiliarias. Por el contrario se aprecia un claro interés por destacar aquellos empleos y títulos honoríficos que evocasen el mínimo indicio de estatus social. Tal es el caso de grados militares (generalmente de oficiales de milicias), cargos de cabildo, hábitos de órdenes militares y, obviamente, Títulos de Castilla. Las menciones más comunes corresponden a grados militares (un total de 16) lo que revela la significación de la institución castrense en la vida social americana por su tradicional relación con la función primigenia de los nobles, los hechos de armas, y su capacidad para ennoblecer a los que la ejercían ${ }^{46}$.

Tabla 4. Oficiales de milicias en los procesos de hidalguía

\begin{tabular}{llll}
\hline \multicolumn{2}{r}{ Pretendientes (Origen) } & $\begin{array}{c}\text { Inicio } \\
\text { proceso }\end{array}$ & Presentado como \\
\hline García de la Puente, Alonso (P) & 1709 & Capitán \\
García de la Puente, Juan (P) & 1709 & Capitán
\end{tabular}

${ }^{42}$ De hecho, el orden de acceso recreaba la jerarquía nobiliaria indiana, dando preferencia, en primer lugar, a los hijos y descendientes de conquistadores y primeros pobladores (beneméritos), después a los hijos de los funcionarios de la Corona, etc. LIRA MONTT, L. (2003). «La Beca del Colegial en los Colegios Mayores y Seminarios Reales de América como acto positivo de la Nobleza». Hidalguía, 298-299, pp. 305-349.

${ }^{43}$ FAYARD, J. (1982). Los miembros del Consejo de Castilla (1621-1746).Madrid: Siglo XXI de España Editores, p. 45.

${ }^{44}$ Sobaler SeCo, Ma. Á. (1987). Los colegiales mayores de Santa Cruz (1484 - 1670): una élite de poder. Valladolid: Junta de Castilla y León, p. 147.

45 Solórzano y Pereira, J. (estudio preliminar por Miguel Ángel Ochoa Brun) (1972). Política Indiana Madrid: Atlas, T. IV. Lib. V, Cap. III, p. 56.

${ }^{46}$ Morales Moya, A. (1988). «Milicia y nobleza en el siglo XVIII (apuntes para una sociología de las armas y de la nobleza en España)». Cuadernos de Historia Moderna, 9, p. 124. 
Gándara Barbeyto, Bernardo de la (P)

Bustamante Quijano, Juan Antonio

(P)

Cevallos, Fernando Antonio (P)

Berindoaga, Juan Félix (P)

Fernández Maldonado, Cayetano (P)

Sánchez de Yebra, José Joaquín (P)

Ugarte, Agustín José (Cr)

Casa y Piedra, Diego Antonio de la (P)

Guerra y Llano, Manuel de la (P)

Fano, Santiago (P)

Arechavala, Juan José de (P)

Páez Jaramillo y Céspedes, Pablo (Cr)

Fuente, José Matías de la (P)

Ochoa de Berrio y Gasteas, Francisco Julián de (P)
Capitán de Infantería española

Capitán del Batallón y comercio de Lima

Coronel

Capitán de Dragones de milicias del valle de Carabaillo

Capitán de Dragones del Regimiento de Milicias del Perú

Capitán de Dragones de Castrovirreina

Capitán de una de las compañías de la nobleza de Lima

Capitán del Batallón de Voluntarios españoles de Lima

Capitán del Regimiento de milicias de Piura

Capitán de la Real Brigada de Artillería

Coronel de milicias agregado de la ciudad de Arequipa

Capitán del Real Cuerpo de Artillería Provincial de milicias de Lima

Subteniente del Real Cuerpo de Artillería del Puerto de El

Callao

1797 Capitán de milicias de caballería de Camaná

FUENTE: ARChV, Sala Hijosdalgo-pleitos, C. 996-3, 976-37, 1056-22, 1184-27, 1146-57, 1048-26, 986-6, 956-29, 1189-45, 1165-14, 1191-30 y 1324-32; Registro-Vizcainías, C. 7-69, 18-5 y 12-19. P.: Peninsular; Cr: Criollo

En la TABLA 4 se presentan los pretendientes que aparecen asociados a un grado militar. Tenemos constancia de que al menos once de ellos -todos de origen peninsular- se dedicaban al comercio ${ }^{47}$. Es el caso del asturiano Juan García de la Puente, identificado como "capitán" en su proceso de hidalguía y especializado en el comercio de telas y paños que desde Lima enviaba al interior, principalmente Cuzco, La Paz y Potosí ${ }^{48}$. En otras ocasiones son las licencias de la Casa de la Contratación las que "delatan" a estos comerciantes. Después de concluir su proceso de hidalguía el pontevedrés Bernardo de la Gándara, a la sazón capitán de "infantería española" ${ }^{49}$, regresaría a Indias como mercader ${ }^{50}$. De igual modo,

47 Juan y Alonso García de la Puente; Bernardo de la Gándara Barbeyto; Juan Antonio de Bustamante Quijano (prior del consulado); Fernando Antonio de Cevallos; Juan Félix de Berindoaga; Cayetano Fernández Maldonado (cónsul del Tribunal de comercio limeño); Diego Antonio de la Casa y Piedra; Manuel de la Guerra y Llano; Santiago Fano; Francisco Julián de Ochoa de Berrio y Gasteas.

${ }^{48}$ En la petición inicial del expediente provisional de hidalguía figuran como "capitanes Juan y Alonso García de la Puente, hermanos y vecinos de Lima" (1709). ARChV, Sala Hijosdalgo-pleitos, C. 1056-22. Testamento otorgado por Alonso García de la Puente, albacea de su difunto hermano Juan García de la Puente. Lima, 26 de abril de 1721. AGN, Notarial, Francisco Estacio Meléndez, prot. 324, ff. 517r-521r.

${ }^{49}$ En la petición inicial del expediente provisional de hidalguía figuran como "Don Andrés de la Gándara Barbeyto, gerpe y chantrero (sic), vecino de la villa de Pontevedra, por sí y en nombre de don Bernardo de la Gándara Barbeyto, capitán de infantería española residente en Indias y de doña 
debemos recordar que la primera referencia explícita hacia un miembro del gremio mercantil en los procesos de hidalguía se halla igualmente ligada a la milicia: Juan Antonio de Bustamante Quijano, presentado como "capitán del batallón y comercio de la ciudad de Lima" $"$, es decir, en una unidad reclutada por el Consulado.

Estos empleos en las milicias adquirieron auténtica relevancia social a partir de los años setenta tras las reformas emprendidas por el virrey Amat que dotaron a estas unidades de una renovada respetabilidad y prestigio que no facilitaba per se la actividad mercantil. Su rápida incorporación a estos cuerpos permitió a los comerciantes relacionarse en pie de igualdad con los miembros de las élites locales. A este enérgico interés contribuyó, como no, la concesión del fuero militar a los oficiales que inhibía la actuación de otras jurisdicciones como, por ejemplo, del tribunal del Consulado sobre los aforados ${ }^{52}$. Así encontramos casos como el de Juan Félix Berindoaga, identificado en 1774 como "capitán de las milicias del valle de Carabayllo en el reino del Perú" ${ }^{53}$, que apenas un año antes se hallaba matriculado en el consulado gaditano como comerciante de la Carrera de Indias ${ }^{54}$.

Con mucha menos frecuencia hallamos pretendientes desempeñando oficios municipales, de acceso mucho más restringido, para los cuales no solo era necesario ser vecino - es decir, residencia estable y casa poblada- sino también contar con cierta reputación en la comunidad. Solo Fernando Antonio de Cevallos figura elegido como alcalde ordinario en la ciudad de Arequipa ${ }^{55}$. Otros pretendientes con cargos municipales se corresponden con oficios enajenados y perpetuos: Domingo Manuel Ortiz de Rozas, regidor perpetuo y decano de

María Manuela y doña Andrea de la Gándara Barbeyto, sus hermanos” (1722). ARChV, Sala Hijosdalgo-pleitos, C. 1324-32.

${ }^{50}$ Información y licencia de Bernardo de la Gándara, mercader, natural de Pontevedra y vecino de Cádiz, hijo de Pedro de la Gándara y de Águeda Barbeyto, a Tierra Firme. Cádiz, 24 de diciembre de 1723. AGI, Contratación, 5473, N. 1, R. 147.

${ }^{51}$ En la petición inicial de su expediente provisional de hidalguía figura como "Don Juan Antonio de Bustamante Quijano, capitán del batallón y comercio de Lima y natural de la villa de Cartes" (1758). ARChV, Sala Hijosdalgo-pleitos, C. 956-29.

52 Marchena FernándeZ, J. (2005). «El Ejército de América antes de la Independencia: ejército regular y milicias americanas, 1750-1815». Estudio histórico. Madrid: Fundación Mapfre Tavera, CD-Rom, p. 153.

53 En la petición inicial del expediente provisional de hidalguía figura como "Don Pedro y su hermano don Juan Félix de Berindoaga, el primero vecino de la villa y corte de Madrid y el segundo capitán de las milicias del valle de Carabayllo en el reino del Perú residente al presente en Lima y antes lo estuvo en dicha villa y corte de Madrid" (1774). ARChV, Sala Hijosdalgo-pleitos, C. 976-37.

${ }^{54}$ Matriculado en 1770. Vid. Ruiz RiverA, J. B. (1988). El consulado de Cádiz..., p. 143.

55 ARChV, Sala Hijosdalgo-pleitos, C. 1048-26. 
Huamanga ${ }^{56}$ (quien por entonces tenía 53 años), y Agustín José de Ugarte, alguacil mayor de Lima ${ }^{57}$.

Resta destacar a aquellos poseedores de las más elevadas distinciones nobiliarias, seis de los cuales estaba en posesión de un título nobiliario (Vid. TABLA 5). Esta aparentemente elevada proporción de aristócratas está condicionada por el número de títulos nobiliarios se concentra el proceso de los cuatro hermanos de la Puente y Castro $^{58}$. En algunos casos, la presencia de estos miembros de la alta nobleza en los procesos resulta especialmente significativa ya que están directamente relacionados con estrategias de perfeccionamiento de la nobleza como la ya citada de Juan Manuel de Sarriá y Cárdenas, beneficiado con el título de conde de Casa Sarriá un año antes ${ }^{59}$ o la de Juan Esteban de la Puente y Castro que había rehabilitado el título de marqués de la Puente y Sotomayor apenas dos años atrás ${ }^{60}$.

Tabla 5. Caballeros y nobles titulados en los procesos de hidalguía

\begin{tabular}{lcl}
\hline \multicolumn{1}{c}{ Pretendientes (Origen) } & $\begin{array}{c}\text { Inicio } \\
\text { proceso }\end{array}$ & $\begin{array}{l}\text { Distinciones nobiliarias (caballeros de } \\
\text { órdenes militares y títulos de nobleza) }\end{array}$ \\
\hline Ortiz de Foronda, Pedro (Cr) & 1753 & Conde de Vallehermoso \\
Abarca, Isidro (P) & 1776 & Caballero de la Orden de Santiago \\
Puente y Castro, Juan Esteban de la (Cr) & 1784 & Marqués de la Puente y Sotomayor \\
Puente y Castro, Lorenzo de la (Cr) & 1784 & Marqués de Villafuerte \\
Puente y Castro, Constanza de la (Cr) & 1784 & Marquesa de Corpa \\
Puente y Castro, Josefa de la (Cr) & 1784 & Condesa de San Pascual \\
Sarriá Cárdenas Segura y Rojas, Juan Manuel & 1793 & Conde de Casa Sarriá \\
de (Cr) & 1801 & Caballero de la Orden de Carlos III \\
Porlier, Antonio Domingo (Cr) & 1801 & Caballero de la Orden de Santiago \\
Porlier, Rosendo (Cr) &
\end{tabular}

FuENTE: ARChV, Sala Hijosdalgo-pleitos, C. 1191-47 y 1208-2; Registro-Vizcainías, C. 14-18. P.: Peninsular; Cr: Criollo.

Si bien es cierto que la mención de estas ocupaciones, cargos y distinciones estaban destinados a resaltar los méritos personales de los interesados, a modo de actos distintivos de nobleza, no tenían un peso decisivo en el fallo final ya que lo que se ponía a prueba en las causas de hidalguía era la calidad de su ascendencia. En cualquier caso, con ello expresaban su condición de fieles súbditos de la

\footnotetext{
${ }^{56}$ ARChV, Sala Hijosdalgo-pleitos, C. 1161-51.

${ }^{57}$ ARChV, Registro-Vizcainías, C. 18-5.

58 ARChV, Registro-Vizcainías, C. 14-18.

59 CADENAS Y VicENT, V. de [et al.] (recopilación y redacción) (1956). Índice nobiliario español. Madrid: Ediciones Hidalguía, p. 148.

${ }^{60}$ Ibídem, p. 403.
} 
Corona, ya como servidores ya como agraciados, y sus nombres quedaban asociados a la respetabilidad que reportaba su cargo o título.

\section{LA LIMPIEZA DE SANGRE EN LOS PROCESOS DE HIDALGUÍA}

Los procesos de hidalguía, concebidos por los pretendientes como prueba de su esclarecida ascendencia, eran una oportunidad no solo para manifestar la posesión de sangre noble sino también otra serie de "reservas" o criterios de inclusión y exclusión. Es lo que Maravall denomina principio de cierre del estamento ${ }^{61}$. En el caso hispano, a la distinción propiamente estamental entre diferentes calidades de sangre (noble y villana) se sumaron otros mecanismos de discriminación que, en origen, no guardaban relación alguna con la hidalguía tales como la limpieza de sangre o los prejuicios respecto a los oficios mecánicos, tenidos como viles y deshonrosos. La cuestión de la limpieza de sangre, surgida durante el siglo XV, cobró especial importancia tras la implantación de los estatutos de limpieza en diferentes instituciones con el fin de excluir a los castellanos nuevos. Por lo tanto, no tenía carácter de filtro estamental sino de tipo étnico-religioso, con un evidente trasfondo socioeconómico. Pero con el tiempo la nobleza, en concreto la nobleza urbana consolidada, acabó adoptando este criterio "como instrumento de preservación de su propia identidad socio-política" ${ }^{\circ 2}$ frente a pujantes sectores económicos deseosos de acceder al estamento privilegiado.

Esta cuestión tuvo una notable importancia en la jurisdicción de la Chancillería vallisoletana donde existían territorios que, de hecho o de derecho, se atribuían una limpieza de sangre inmemorial, convirtiendo la propia procedencia geográfica en una garantía de limpieza socialmente aceptada. Esta doble estructura castizoestamental logró un perfeccionamiento jurídico en los fueros de Vizcaya y Guipúzcoa según los cuales estos territorios quedaban definidos, por un lado, como solares de nobleza y, por otro, como zonas libres de toda infección obligando a todo aquel que desease tomar vecindad a probar su nobleza y limpieza que, por lo tanto, eran requisitos indispensables para ser reconocidos como pobladores originarios $^{63}$. De modo que para los oriundos de estos territorios los procesos de

${ }^{61}$ Maravall, J. A. (1989). Poder, honor y elites en el siglo XVII. Madrid: Siglo XXI de España Editores, p. 80.

${ }^{62}$ GutiÉRREZ NieTO, J. I. (1973). «Estructura castizo-estamental de la sociedad castellana del siglo XVI». Hispania, 125, p. 540.

${ }^{63}$ En Vizcaya, dada la condición de hijosdalgo y limpios de sangre de todos sus pobladores, se prohibía expresamente el avecindamiento en el Señorío de aquellos de origen judío y moro y se exigía hacer información de su linaje a los que se asentasen en él. AREITIO y Mendiolea, D. de 
hidalguía o vizcainía se convertían en una evidencia documental del doble sistema de exclusión del honor.

De hecho resulta habitual que los pretendientes indianos manifiesten en los poderes su deseo de acreditar su condición de "hijo legítimo así como de ser él y sus ascendientes españoles, cristianos viejos, limpios de mala raza, caballeros notorios hijosdalgo" ${ }^{64}$ o que "se me califique hasta el cuarto abolengo por ambas líneas de que soy y fueron mis padres y lo son actualmente y demás antepasados cristianos viejos limpios de toda mala raza de moros, judíos, serfarios (sic) ni de los nuevamente convertidos... y de que somos caballeros notorios hijosdalgo de casas y solares conocidos por tales..." ${ }^{\text {; }}$; o incluso expresando todas las cualidades propias de una esclarecida ascendencia mediante "información ad perpetuam rei memoriam de la cristiandad y limpieza, calidad, hidalguía y nobleza de los dichos mis padres, mía y de mis abuelos hasta en el grado que se acostumbra o fuere necesario..." $"$.

De este modo, aunque en la Sala de Hijosdalgo nunca se exigía que las partes demostrasen limpieza de sangre, eran los propios pretendientes los que, voluntariamente, sentían la necesidad de que apareciese esta información en los procesos a través de las probanzas con declaración de testigos. En cierto modo, este aprecio por la limpieza de sangre y el deseo de hacerla constar junto a la hidalguía recuerda un conocido adagio de la época según el cual "si honrado era ser hidalgo más afrentoso era no ser limpio porque en España se estimaba más al pechero limpio que al hidalgo que no lo era" ${ }^{, 67}$. De hecho, tras hacer un somero sondeo en procesos incoados por residentes en la Península se observa que estas alusiones a la limpieza de sangre no eran en absoluto una norma general ya que el contenido de las preguntas de los interrogatorios suele limitarse a determinar la legitimidad, exención y actos distintivos de los articulantes. Esto sitúa los interrogatorios en las

(Introducción y notas) (1950). El Fuero, privilegios, franquezas y libertades del Muy Noble y Muy Leal Señorío de Vizcaya Bilbao: Diputación Foral de Vizcaya, Tít. I, 1. XIII.

${ }^{64}$ Poder notarial otorgado por Pascual Fernández de Linares. Lima, 16 de enero de 1721. ARChV, Sala Hijosdalgo-pleitos, C. 926-57.

65 Poder notarial otorgado por José Antonio Santander Alvarado. Lima, 28 de abril de 1737. ARChV, Sala Hijosdalgo-pleitos, C. 929-89.

${ }^{66}$ Poder notarial otorgado por Isidro de Sierralta. Huancavelica, 12 de diciembre de 1720. ARChV, Sala Hijosdalgo-pleitos, C. 1076-65.

${ }^{67}$ Así reza en el "Papel que dio el Reino de Castilla a uno de los Señores Ministros de la Junta diputada para tratarse sobre el memorial presentado por el Reino a Su Majestad con el libro del Padre Maestro Salucio en punto de probanza de la limpieza y nobleza de estos Reinos". Biblioteca Nacional de España [en adelante BN], Manuscrito, 13.043. Citado por SicrofF, A. A. (1985). Los estatutos de limpieza de sangre. Controversias entre los siglos XV y XVII. Madrid: Taurus, pp. 209-210. 
probanzas de los indianos más cerca de las pruebas para la admisión en las órdenes militares que de las que debían corresponder a una probanza de hidalguía.

En una sociedad como la indiana, caracterizada por una gran complejidad étnica, no podemos dudar de la trascendencia que tenía esta cuestión, reformulando el concepto de pureza de sangre sobre la base de la "hispanidad" (descendencia de españoles) y la "blancura" (descendencia de blancos) ${ }^{68}$. En América, la dificultosa definición del concepto de nobleza propició que la noción de limpieza cobrase una mayor importancia como requisito necesario para acceder a determinadas corporaciones de prestigio como cabildos seculares y eclesiásticos, colegios mayores, etc. Una vitalidad que, como hemos mencionado, también se puso de manifiesto a través de su apetencia por los puestos en el Santo Oficio. Un buen ejemplo es el del comerciante pontevedrés Bernardo de la Gándara y Barbeyto quien, deseoso de perfeccionar su ascendencia, obtuvo el reconocimiento de su hidalguía en Chancillería al mismo tiempo que su nombramiento de familiar del Santo Oficio de Lima ${ }^{69}$.

La complejidad étnica de la sociedad americana actuaría como el catalizador adecuado bajo cuyos parámetros se reproducirían nuevas formas de exclusión, sustituyendo la superioridad del cristiano viejo frente al cristiano nuevo por la del español blanco frente al resto de grupos étnicos y sus respectivas castas. De este modo, a la tradicional fórmula ritual que definía a los pretendientes como "limpios de sangre sin mancha de moros, judíos, conversos ni penitenciados por el Santo Tribunal de la Inquisición" se unirían otros elementos propios de la sociedad indiana. Un buen ejemplo es el caso de los navarros Juan Félix y Pedro de Berindoaga en cuya probanza se pregunta a los testigos del valle del Baztán:

"Si los suplicantes y sus ascendientes paternos y maternos han sido cristianos viejos, limpios de pura y limpia sangre, sin mezcla raza ni mancha

68 MARTíneZ, Ma E. (2008). Genealogical fictions: limpieza de sangre, religion and gender in colonial México. Stanford: Standford University Press, p. 248.

${ }^{69}$ Expediente provisional de hidalguía de Andrés de la Gándara Barbeyto, vecino de la villa de Pontevedra, por sí y en nombre de Don Bernardo de la Gándara Barbeyto, capitán de infantería española residente en Indias y de Doña María Manuela y Doña Andrea de la Gándara Barbeyto, sus hermanos (1722). ARChV, Sala Hijosdalgo-pleitos, C. 1324-32. Información genealógica de Bernardo Gándara y Barbeyto, natural de Santa Eulalia de Gil y pretendiente a oficial del Santo Oficio (1722). AHN, Inquisición, 1403, exp. 7. 
de moros, judíos, agotes, hugonotes, negros, mulatos, penitenciados por la Santa Inquisición ni otra secta en derecho reprobada..."70.

Algunos de estos términos tienen además un marcado significado local como "agotes", pueblo asentado en el valle del Baztán discriminado por la población nativa por razones religiosas y étnicas ${ }^{71}$. En cuanto a la presencia del término "hugonote" parece deberse no tanto a la cercanía de Navarra con el reino de Francia como a la procedencia del padre de los Berindoaga, Pedro de Berindoaga y de Arriet (nacido en la provincia francesa de Labort, limítrofe con el valle de Baztán), disipando con ello cualquier duda sobre su confesión, descartando así toda sospecha que pudiese vincularlo con la herejía protestante, un matiz de orden religioso directamente relacionado con la coletilla final de "penitenciados por la Santa Inquisición ni otra secta en derecho reprobada". Pero también vemos como se introducen aquí, junto a estos tradicionales estereotipos negativos, criterios étnicos ajenos no solo a la realidad navarra sino también a la peninsular ya que proceden de una noción de limpieza de sangre netamente americana: "sin raza ni mancha de negros y mulatos". Esto es una evidencia tanto del conocimiento que poseían los Berindoaga sobre los criterios de exclusión social vigentes en Indias como de su deseo de acomodar su ascendencia a ellos.

Los pretendientes que manifestaban un mayor interés por demostrar su limpieza eran, sin duda alguna, los peninsulares y criollos de origen vascongado que introducían la especificidad americana en los interrogatorios. Es el caso de la guayaquileña Francisca de Lecuona. Interrogados los testigos sobre su familia paterna, procedente de la ciudad donostiarra de San Sebastián, no solo se les preguntó sus miembros eran limpios de moros, judíos y agotes sino también de

${ }^{70}$ Pregunta $n^{\text {o }} 4$ del interrogatorio realizado a los testigos presentados en el valle de Baztán (1770). Presentado como prueba en el Expediente provisional de hidalguía de los hermanos Pedro y Juan Félix de Berindoaga (1774). ARChV, Sala Hijosdalgo-pleitos, C. 976-37.

${ }^{71}$ Resulta interesante observar como estos prejuicios respecto a los agotes no se circunscriben únicamente al reino navarro sino que también tuvieron una considerable influencia sobre las provincias cercanas como Guipúzcoa o Vizcaya, haciendo acto de presencia incluso en los interrogatorios de los pretendientes criollos que descendían de aquellos territorios. Es el caso de la guayaquileña Francisca Plácida de Lecuona y Alberro, hija del donostiarra José Antonio Lecuona y Alberro. ARChV, Sala Hijosdalgo-pleitos, C. 1047-28. El conde de Casa Sarriá, limeño avecindado de Cádiz y nieto del también guipuzcoano Lorenzo de Sarriá Corcostegui, natural de Legazpia. ARChV, Sala Hijosdalgo, C. 1191-47. El iqueño Francisco Iturrate y Bernaola, hijo de Francisco de Iturrate, natural de Dima (Vizcaya). ARChV, Registro-Vizcainías, C. 8-55; de los panameños Icaza y Caparroso, hijos de Juan Martín Icaza Urigoitia, natural de Ochandiano (Vizcaya). ARChV, RegistroVizcainías, C. 8-40; o de los limeños de la Puente y Castro, hijos de Lorenzo de la Puente y Larrea, natural del valle de Trucíos (Vizcaya). ARChV, Registro-Vizcainías, C. 14-18. 
"mulatos" $"$. Es más, cuanto más distinguida era una familia mayor era su inquietud por estas cuestiones. Un buen ejemplo son los hermanos De la Puente y Castro. Estos aristócratas expresaron su preocupación por la limpieza de sangre a través de una meticulosa y ceremonial pregunta formulada a los testigos de la tierra de sus antepasados:

"Si saben que los expresados don Lorenzo Antonio de la Puente, doña Ana de Castro Urdanegui Delgadillo, don Antonio de la Puente y Calera, doña María de Larrea y Garma, don Pedro de la Puente, doña Francisca de Calera, don Felipe de Larrea y doña María de la Garma, padres, abuelos y bisabuelos del expresado doctor don Juan Esteban de la Puente han sido y son de sí y sus mayores antepasados cristianos viejos limpios de toda mala raza de moros, agotes, judíos o recién conversos no penitenciados por el Santo Oficio de la Inquisición u otro tribunal o persona que haya ejercido su jurisdicción como delincuente sospechoso en alguna de dichas sectas u otra prohibida o no recibida por nuestra Madre la Iglesia y sus sagrados concilios antes de que proceden respectivamente, han sido y son obedientes a la dicha Madre Iglesia, sus prelados y ministros, puntualmente observantes de nuestra Sagrada Ley, sus mandamientos, muy religiosos en ella y en todo acto de piedad y religión dando con sus vidas y costumbres ejemplo a los demás y procurando en ellos esmero, observancia y toda especie de virtud, digan...,73.

Este estilo cuidado y sumamente protocolario de las preguntas estaba en consonancia con el estatus correspondiente a esta familia, de la que no podía sospecha alguna sobre su reputación, ni siquiera sobre su condición de súbditos leales:

"Si saben que el pretendiente, sus padres y abuelos y bisabuelos hayan ejercido por sí mismos oficios viles o mecánicos que les haya privado o suspendido de las preeminencias y regalías correspondientes a su notoria hidalguía o si han cometido algún delito lesa Magestatis divina o humana u otro por el que hayan caído en infamia o menos valer" ${ }^{\text {, }}$.

Esta referencia a la "limpieza" de todo delito de lesa magestatis evoca la adhesión familiar al monarca, una clara manifestación de la teoría política

\footnotetext{
72 Interrogatorio de testigos realizado en San Sebastián (1759). Presentado como prueba en la información ad perpetuam rei memoriam de Francisca Lecuona y Alberro (1778). ARChV, Sala Hijosdalgo-pleitos, C. 1047-28.

73 Pregunta $n^{\circ} 4$ del interrogatorio realizado a los testigos presentados en el Valle de Trucíos (1782). Presentado como prueba en la Real Provisión de vizcaína de los hermanos de la Puente y Castro (1784). ARChV, Registro-Vizcainías, C. 14-18.

${ }^{74}$ Pregunta $\mathrm{n}^{\circ} 6$ del interrogatorio. Ibídem.
} 
absolutista donde la lealtad a este era una de las obligaciones del buen súbdito ${ }^{75}$, más aún para miembros de la alta nobleza como los De la Puente y Castro. Esta noción de delito de "lesa magistatis divina y humana" está relacionada no solo con la noción del regicidio, sino también con su vertiente religiosa, el "deicidio", y, por lo tanto, con el pueblo deicida por antonomasia, los judíos ${ }^{76}$.

En la vieja controversia sobre la relación entre nobleza y limpieza de sangre cabe mencionar como ejemplo paradigmático el entronque de Juan Manuel Sarriá y Cárdenas, conde de Casa Sarriá. Este limeño avecindado en Cádiz demostró un gran interés en acreditar la antigüedad y distinción de su filiación por todas las líneas remontando su ascendencia materna hasta el linaje converso de los Coronel, de los que descendía por parte de su bisabuela paterna-materna. El fundador de este linaje fue Hernán Pérez Coronel (antes llamado Abrahem Senior), un reconocido converso segoviano premiado por los Reyes Católicos con un privilegio de hidalguía poco después de su bautismo ${ }^{77}$. Aunque resulta llamativa esta circunstancia, no debemos olvidar que en estos procesos se juzgaba exclusivamente la hidalguía, no la limpieza de sangre, y que aunque lo deseable socialmente era tener ambas calidades, no podía desdeñarse la posibilidad de acreditar el entronque con un linaje notable como el de los Coronel. Además, hemos de considerar que a finales del siglo XVIII el furor anticonverso había perdido fuerza y las posibles máculas de los Coronel habían quedado muy lejanas en el tiempo.

75 Díaz de la Guardia y LóPEZ, L. (2003). «El deber de fidelidad al Rey...», pp. 121-122. También en relación con la cuestión de la lealtad al monarca, queremos destacar la existencia de una serie de "figuras" convertidas en sinónimo de deslealtad dentro de la mentalidad indiana. Sus orígenes se hallan en los conflictos surgidos entre los conquistadores-encomenderos y la Corona durante las primeras etapas de la Conquista y cuyo rechazo a ellos y a sus familias se perpetuará durante los siglos posteriores. Así se pone de manifiesto en la información de testigos presentada como prueba en el Expediente provisional de hidalguía de los hermanos Gallo. Interrogados sobre los orígenes familiares de Juan Gallo, padre de los pretendientes, los declarantes manifiestan que no descendía "del abolengo de Pisarros, Colonos [Colones] ni Conteses [Corteses]". Información de testigos de Juan Gallo (1727). Documento incorporado como prueba en el proceso los hermanos Gallo Díaz Calvo (1790). ARChV, Sala Hijosdalgo-pleitos, C. 996-5. Esta atípica "pureza de sangre" se hacía constar igualmente a la hora de solicitar hábitos militares. LOHMANN VILlENA, G. (1947). Los americanos en las órdenes nobiliarias: (1529-1900). Madrid: Instituto Gonzalo Fernández de Oviedo, I, p. LIX.

${ }^{76}$ OREJÓN Y HARO, A. de (1795). Apuntamientos sobre la hidalguía y colección de fórmulas para todos los recursos de esta naturaleza. Con la instrucción que debe dirigir la de los extranjeros, conforme con la práctica que observa la Sala de los señores Alcaldes de los hijosdalgo de la Real Chancillería de Granada. Málaga: Imprenta de Luis Carreras, pp. 14-17.

77 Sobre los orígenes del linaje de los Coronel Ladero QuESADA, M. A. (2003). "Coronel, 1492. De la aristocracia judía a la nobleza cristiana en la España de los Reyes Católicos". Boletín de la Real Academia de la Historia, 200-1, pp. 11-24. 


\section{CONSIDERACIONES FINALES}

El historiador debe ser consciente que la fuente primaria, el documento histórico, no siempre es un instrumento objetivo sino que está impregnado de subjetividad, una cualidad de la que podemos sacar partido. Este planteamiento adquiere plena vigencia en los procesos de hidalguía donde los silencios e informaciones sesgadas, bastante frecuentes, tienen un claro significado dentro del derecho y la mentalidad nobiliaria. La diferencia entre "quién dice ser" y quien era realmente el pretendiente demuestran la distancia existente entre teoría estamental y realidad social.

El análisis de la información aportada en los procesos de hidalguía sobre los pretendientes revela aspectos cruciales y poco estudiados sobre la mentalidad nobiliaria, demostrando las contradicciones de la sociedad a finales del Antiguo Régimen. La mención interesada de apellidos, cargos, actividades y títulos forma parte del ideario nobiliario, destinado a transmitir y exteriorizar una imagen idealizada del pretendiente omitiendo todos aquellos aspectos que pudiesen ensombrecer sus pretensiones. De este modo, los grados en los cuerpos de milicias, los puestos en la administración indiana, los hábitos de órdenes militares o los títulos nobiliarios alcanzan en los procesos un gran valor simbólico como signos de estatus e incluso como actos positivos de nobleza.

Junto a los signos distintivos de nobleza también harán acto de presencia en los procesos de hidalguía criterios de exclusión. Así, los prejuicios hacia las actividades consideradas poco compatibles con la nobleza se hacen patente a través de los silencios y omisiones sobre la actividad mercantil por parte de los propios interesados, que intentarían de este modo mantener separados ocupación de su estatus como hidalgo de sangre. Parece evidente que las reformas impulsadas por la monarquía para dignificar trabajos como el comercio o los oficios mecánicos tardaron en ser asumidas por la población. Otro de los criterios de exclusión, la limpieza de sangre, puede rastrearse igualmente de manera más o menos acusada en todos los procesos de hidalguía, reflejando las adaptaciones al estatus social y entorno geográfico del pretendiente.

En resumen, los procesos de hidalguía demuestran que hidalguía de sangre, limpieza de oficios y limpieza de sangre se mantenían a finales del Antiguo Régimen como pilares de la identidad nobiliaria, tanto en España como en la compleja realidad americana, formando parte del sistema que amparaba los privilegios del estamento noble. 